\title{
Analisis Usahatani Wortel (Daucus carota L) Organik dan Non Organik \\ (Studi Kasus pada Pusat Pelatihan Pertanian dan Perdesaan Swadaya (P4S) Eka Setia Lestari, Desa Bangli, Kecamatan Baturiti, Kabupaten Tabanan)
}

\author{
GDE NUSHA SUPUTRA, I WAYAN WIDYANTARA, \\ IDA AYU LISTIA DEWI
}

\author{
Program Studi Agribisnis, Fakultas Pertanian, Universitas Udayana \\ Jalan PB Sudirman Denpasar 80232 \\ Email: nushasucipta@gmail.com \\ widyantara@yahoo.com
}

\begin{abstract}
The Organic and Non Organic Carrot Farming Analysis (Case Study on P4S Eka Setia Lestari, Bangli Village, Baturiti Sub-District, of Tabanan Regency)
\end{abstract}

The objectives of the research are to determine the differences of income of the organic and non organic carrot farming. The second objective is to find out the constraints faced by the organic and non organic farmers.The research was conducted in Bangli Village, Baturiti Sub-District, Tabanan Regency. Determination of the location is done purposively because Eka Setia Lestari already has organic certificate and recognized by the LeSos Organic Institute. The respondents were farmers who planted carrots during the planting season of September - December 2015 at P4S Eka Setia Lestari with the number of 24 people. Determination of respondents of the research was conducted by census method. The analysis used was farm income analysis, Mann Whitney test, and descriptive analysis. The results showed that the organic carrot income was $\mathrm{Rp} 7,646,446.67$ and non-organic carrot

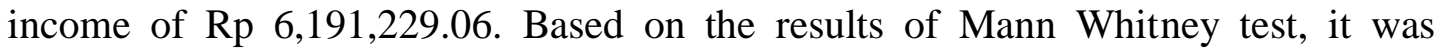
obtained significant differences between the incomes of farmers who grew organic and non-organic carrots. The constraint faced by the organic carrot farmers is that carrots are more susceptible to pests and diseases attacks while the constraint experienced by the non-organic carrot farmers is the price fluctuations in the sale of carrots in the market.

Keywords: farm income, carrot, organic, non organic

\section{Pendahuluan}

\subsection{Latar Belakang}

Pertanian organik merupakan salah satu alternatif budidaya pertanian yang berwawasan lingkungan dan berkelanjutan yang bebas dari segala bentuk bahan anorganik seperti pupuk buatan, pestisida, dan zat pengatur tumbuh. Pertanian organik memadukan berbagai cara seperti pergiliran tanaman, tumpangsari, penggunaan sisa bahan organik sebagai pupuk, serta pengendalian hama secara 
terpadu dengan mengoptimalkan cara biologis (Untung, 1994). Kecenderungan seperti ini membuka suatu peluang baru dalam bisnis di bidang pertanian terutama tanaman hortikultura yang produknya sering dikonsumsi secara langsung atau dalam keadaan segar (Sunu, et al. 2006). Filosofi yang melandasi pertanian organik adalah mengembangkan prinsip-prinsip memberi makan pada tanah yang selanjutnya tanah menyediakan makanan untuk tanaman (feeding the soil that feeds the plants), dan bukan memberi makanan langsung pada tanaman. Von Uexkull dalam Sutanto (2006) memberikan istilah "membangun kesuburan tanah" strategi pertanian organik adalah memindahkan hara secepatnya dari sisa tanaman, kompos dan pupuk kandang menjadi biomassa tanah yang selanjutnya setelah mengalami proses mineralisasi baru menjadi unsur dalam larutan tanah. unsur hara di daur ulang melalui satu atau lebih tahapan bentuk senyawa organik sebelum diserap tanaman.

Usahatani organik merupakan sistem pertanian yang padat karya dengan bergantung pada ketekunan tenaga manusianya. Pertanian dengan sistem organik ini memberikan berbagai keuntungan, secara teknis dapat mengembalikan kesuburan tanah, secara ekonomis menjanjikan keuntungan yang lebih besar dan secara medis dapat menyehatkan masyarakat. Biaya produksi dalam menghasilkan bahan pangan organik cukup mahal, sehingga harga jualnya di pasaran pun akan jauh lebih tinggi dibandingkan bahan pangan non organik.

Sayuran memainkan peran yang sangat penting sebagai sumber nutrisi bagi tubuh manusia dan mereka yang mengonsumsi sayuran memastikan asupan penting berbagai vitamin dan unsur mineral terpenuhi sehingga menghindari masalah gizi di kalangan anak-anak dan wanita hamil, serta bertanggung jawab atas tingkat kematian yang tinggi dari kelompok-kelompok ini. Kurangnya konsumsi sayuran dan buahbuahan setiap tahunnya menyebabkan 2,7 juta kematian di seluruh dunia, dan merupakan salah satu dari sepuluh faktor risiko terhadap manusia yang mortalitas (Oladele, 2011).

Wortel merupakan salah satu komoditas sayuran yang menjadi sasaran penanaman secara organik dan mempunyai prospek pemasaran yang cerah karena wortel merupakan sayuran bernilai ekonomis penting di dunia. Bali merupakan salah satu penghasil produksi wortel, namun tidak banyak petani holtikultura di Bali yang melakukan penanaman tanaman wortel penghasilan tertinggi produksi wortel di Bali pada tahun 2007 mencapai 5.592 ton dan penghasilan produksi wortel terendah di Bali sebanyak 3.417 ton pada tahun 2009 (BPS Bali, 2013). Harga memang menjadi perangsang aktivitas petani, namun kepastian pasar juga sangat penting. Petanipetani sayuran organik di Desa Bangli, Kecamatan Baturiti, Kabupaten Tabanan akhirnya membentuk wadah dengan tujuan memperoleh kepastian pasar yang bernama Pusat Pelatihan Pertanian dan Perdesaan Swadaya (P4S) Eka Setia lestari.

Perkembangan kelompok ini tidak hanya untuk kepentingan kepastian harga pasar tetapi sebagai sebagai tempat pelatihan-pelatihan teknologi baru bagi tanaman holtikultura, anggota yang ikut bergabung tidak hanya petani organik namun terdapat juga petani non organik yang tergabung dalam pusat pelatihan ini. Wortel merupakan 
salah satu tanaman yang dikelola secara organik dan non organik di kelompok tersebut, sehingga diadakan penelitian ini untuk mengetahui apakah memang benar terdapat perbedaan pendapatan usahatani secara organik dan non organik.

\subsection{Rumusan Masalah}

Berdasarkan latar belakang yang telah dipaparkan di atas, dapat dirumuskan suatu masalah, beberapa permasalahan sebagai berikut :

1. Apakah ada perbedaan dari pendapatan usahatani wortel organik dan non organik?

2. Apa kendala-kendala yang dihadapi oleh para petani dalam usahatani wortel organik dan non organik?

\subsection{Tujuan Penelitian}

Berdasarkan perumusan masalah yang telah di uraikan, maka tujuan dari penelitian ini adalah sebagai berikut :

1. Mengetahui perbedaan pendapatan usahatani dari wortel organik dan non organik.

2. Mengetahui kendala-kendala yang dihadapi petani dalam bidang wortel organik dan non organik.

\section{Metode Penelitian}

\subsection{Lokasi dan Waktu penelitian}

Penelitian ini dilaksanakan pada Pusat Pelatihan Pertanian dan Perdesaan Swadaya (P4S) Eka Setia Lestari di Desa Bangli, Kecamatan Baturiti, Kabupaten Tabanan. Penentuan lokasi ini dilakukan secara sengaja dengan pertimbangan bahwa usaha agribisnis Pusat Pelatihan Pertanian dan Perdesaan Swadaya (P4S) Eka Setia Lestari sudah diakui oleh Lembaga Organik LeSos dan Pusat Pelatihan Pertanian dan Perdesaan Swadaya (P4S) Eka Setia Lestari telah memiliki sertifikat dari Lembaga Organik LeSos sebagai bukti bahwa petani pada P4S Eka Setia lestari telah melakukan penanaman sayuran secara organik.

\subsection{Populasi, Sampel, dan Responden Penelitian}

Responden dalam penelitian ini adalah petani yang menanam wortel pada musim tanam September - Desember 2015 baik secara organik maupun non organik pada Pusat Pelatihan Pertanian dan Perdesaan Swadaya (P4S) Eka Setia Lestari dengan jumlah 24 orang. Teknik pengambilan sampel dalam penelitian ini dengan metode sensus atau semua populasi dijadikan sampel. Responden penelitian adalah kepala keluarga dari petani yang melakukan penanaman wortel.

\subsection{Teknik Pengumpulan Data, Variabel Penelitian, dan Metode analisis}

Data primer yang dipergunakan dalam penelitian ini yaitu identitas responden, jumlah produksi wortel, harga jual produksi wortel, biaya bibit, biaya pupuk, biaya 
obat, biaya tenaga kerja, biaya sewa traktor, dan nilai peralatan. Data sekunder yang digunakan pada penelitian ini adalah jumlah produksi wortel dari daerah yang diteliti dan kelompok tani yang menanam wortel yang diperoleh dari perusahaan dan instansi yang berkaitan dengan penelitian. Teknik pengumpulan data yang dipergunakan adalah metode survey yaitu pengamatan secara langsung dan metode wawancara dengan cara menyebarkan kuisioner kepada petani wortel baik yang organik maupun yang non organik. Metode yang terakhir adalah dokumentasi yaitu mengumpulkan data yang dilakukan oleh peneliti dengan cara mengambil gambar berupa foto-foto serta melakukan studi pustaka.

Data penelitian yang telah terkumpul kemudian ditabulasikan dan dianalisis. Analisis pertama mencari nilai pendapatan usahatani wortel organik dan non organik. Langkah selanjutnya adalah melakukan uji Mann Whitney untuk menentukan perbedaan pendapatan usahatani wortel organik dan non organik. Hipotesis Nol (H0) pada uji ini adalah tidak adanya perbedaan signifikan pada pendapatan usahatani antara wortel organik dan non organik, kendala-kendala yang muncul dianalisis mempergunakan analisis deskriptif.

\section{Hasil dan Pembahasan}

\subsection{Biaya Usahatani}

Mubyarto (1989) menyatakan, bahwa biaya produksi adalah semua pengeluaran yang diperlukan untuk menghasilkan sejumlah produk tertentu dalam satu kali proses produksi. Biaya produksi dapat digolongkan atas dasar hubungan perubahan volume produksi, yaitu biaya tetap dan biaya variabel. Biaya tetap merupakan biaya yang besar kecilnya tidak dipengaruhi oleh besar kecilnya produksi, sedangkan biaya variabel adalah jenis biaya yang besar kecilnya berhubungan dengan besar kecilnya produksi. Secara keseluruhan biaya tetap dan biaya variabel yang dikeluarkan dalam proses produksi merupakan biaya total produksi. Hal ini sejalan dengan pendapat Soeharjo dan Patong (1973) yang menyatakan, bahwa biaya total dalam suatu proses produksi adalah jumlah biaya tetap total dan biaya variabel total.

Hasil penelitian diperoleh bahwa biaya produksi usahatani wortel organik dan non organik di Desa Bangli, Kecamatan Baturiti, Kabupaten Tabanan terdiri dari biaya tetap dan biaya variabel. Biaya tetap pada penelitian ini meliputi biaya penyusutan alat pertanian, sedangkan biaya variabel pada penelitian ini meliputi biaya sewa traktor, biaya benih, pupuk, obat-obatan, dan upah tenaga kerja dalam maupun luar keluarga. Berdasarkan luas lahan per hektar biaya total yang dikeluarkan oleh responden wortel organik lebih sedikit dibandingkan biaya total yang dikeluarkan responden wortel non organik. Komponen biaya terbesar yang dikeluarkan responden usahatani wortel organik adalah sewa traktor, sedangkan biaya terbesar yang dikeluarkan responden usahatani wortel non organik adalah sewa pick up. Berikut dapat dilihat struktur biaya usahatani yang dikeluarkan oleh responden wortel organik dan non organik pada tabel 1 berikut. 
Tabel 1.

Rata-rata Biaya Usahatani Wortel secara Organik dan Non Organik Periode Musim Tanam September - November 2015

\begin{tabular}{|c|c|c|c|c|c|c|}
\hline No & \multicolumn{2}{|c|}{ Uraian Proporsi Biaya } & $\begin{array}{c}\text { Organik } \\
\text { (Rp/LLG) }\end{array}$ & $\begin{array}{c}\text { Non Organik } \\
\text { (Rp/LLG) }\end{array}$ & $\begin{array}{l}\text { Organik } \\
(\mathrm{Rp} / \mathrm{Ha})\end{array}$ & $\begin{array}{c}\text { Non Organik } \\
(\mathrm{Rp} / \mathrm{Ha})\end{array}$ \\
\hline A. & \multicolumn{6}{|c|}{ Biaya Tetap } \\
\hline 1 & \multicolumn{2}{|c|}{ Penyusutan Cangkul } & $18.466,67$ & $12.792,52$ & $168.333,33$ & $56.917,02$ \\
\hline 2 & \multicolumn{2}{|c|}{ Penyusutan Keranjang } & $16.975,00$ & $17.928,57$ & $150.305,56$ & $82.046,96$ \\
\hline 3 & \multicolumn{2}{|c|}{ Penyusutan Pisau } & $2.391,67$ & $2.903,06$ & $18.256,94$ & $13.351,47$ \\
\hline \multicolumn{3}{|c|}{ Total Biaya Tetap } & $37,833,33$ & $33.624,15$ & $336.895,83$ & $152.315,45$ \\
\hline B. & \multicolumn{6}{|c|}{ Biaya Variabel } \\
\hline 1 & \multicolumn{2}{|c|}{ Sewa Traktor } & $330.000,00$ & $330.000,00$ & $2.915 .000,00$ & $1.531 .394,56$ \\
\hline 2 & \multicolumn{2}{|c|}{ Benih } & $112.400,00$ & $182.000,00$ & $762.666,67$ & $808.349,21$ \\
\hline 3 & \multicolumn{2}{|c|}{ Pick Up } & - & $190.000,00$ & - & $2.633 .401,36$ \\
\hline \multirow[t]{5}{*}{4} & \multicolumn{6}{|c|}{ Pupuk } \\
\hline & a. & NPK & - & $52.242,86$ & - & $229.671,43$ \\
\hline & b. & KCL & - & $17.710,00$ & - & $76.752,72$ \\
\hline & & SP-36 & - & $22.428,57$ & - & $97.337,87$ \\
\hline & & Organik & $35.000,00$ & $28.125,00$ & $230,416,67$ & $123.497,73$ \\
\hline 5 & & isida & - & $21.911,79$ & - & $96.966,51$ \\
\hline \multirow[t]{3}{*}{6} & \multicolumn{6}{|c|}{ Tenaga Kerja } \\
\hline & \multicolumn{2}{|c|}{ TKDK } & $321.432,50$ & $332.032,14$ & $2.314 .829,17$ & $1,482.501,02$ \\
\hline & \multicolumn{2}{|c|}{ TKLK } & $96.887,50$ & $109.053,57$ & $631.958,33$ & $481.246,60$ \\
\hline \multicolumn{3}{|c|}{ Total Biaya Variabel } & $895.720,00$ & $1.285 .503,93$ & $6.854 .870,83$ & $7.561 .119,01$ \\
\hline \multicolumn{3}{|c|}{ Total Biaya Usahatani } & $933.553,33$ & $1.319 .128,08$ & $7.191 .766,67$ & $7.713 .434,46$ \\
\hline
\end{tabular}

Sumber : diolah dari data primer 2016

Tabel 1 menunjukkan bahwa petani organik mengeluarkan total biaya usahatani sebesar Rp 933.553,33 sedangkan petani non organik mengeluarkan biaya usahatani sebesar Rp 1.319.128,08. Berdasarkan penjelasan diatas terdapat perbedaan biaya-biaya yang dikeluarkan antara kedua petani responden yaitu biaya benih, pupuk, insektisida, tenaga kerja, penyewaan traktor dan pick up. Petani responden penanaman secara non organik harus mengeluarkan biaya lebih banyak untuk membeli Pupuk NPK, KCL, dan Sp-36. Responden metode penanaman secara non organik juga mengeluarkan biaya untuk membeli insektisida serta menggunakan pick up untuk membawa hasil produksi ke pasar terdekat. Responden penanaman secara organik tidak mengeluarkan biaya pupuk KCL, NPK, dan SP-36 serta insektisida dan sewa kendaraan karena petani responden penanaman secara organik hanya menggunakan pupuk organik.

Biaya variabel yang dikeluarkan oleh responden metode penanaman secara non organik lebih banyak jika dibandingkan dengan responden metode penanaman secara organik. Penggunaan benih, pupuk, insektisida, dan pick up yang lebih besar 
menyebabkan responden metode penanaman secara non organik mengeluarkan biaya lebih besar. Rendahnya biaya variabel pada petani organik disebabkan oleh kondisi lahan garapan sudah sangat baik, sehingga mampu menerapkan sistem organik murni. Responden organik di pusat pelatihan ini sudah tiga tahun terbebas sepenuhnya dari penggunaan bahan-bahan kimia pabrik.

\subsection{Penerimaan Usahatani}

Menurut Soekartawi (1986) penerimaan usahatani adalah nilai yang diterima dari penjualan produk usahatani dengan kata lain perkalian antara produksi yang diperoleh dengan harga jual. Penerimaan yang dimaksud pada penelitian ini adalah hasil penjualan wortel yang diperoleh petani Eka Setia Lestari. Berikut penerimaan usahatani wortel antara kedua kelompok responden dapat dilihat pada tabel 2 berikut.

Tabel 2.

Penerimaan Usahatani Wortel secara Organik dan Non Organik Periode Musim Tanam September - November 2015

\begin{tabular}{clccccc}
\hline no & Metode & $\begin{array}{c}\text { Harga } \\
(\mathrm{Rp})\end{array}$ & $\begin{array}{c}\text { Produksi } \\
(\mathrm{Kg} / \mathrm{LLG})\end{array}$ & $\begin{array}{c}\text { Produksi } \\
(\mathrm{Kg} / \mathrm{Ha})\end{array}$ & $\begin{array}{c}\text { Penerimaan } \\
(\mathrm{Rp} / \mathrm{LLG})\end{array}$ & $\begin{array}{c}\text { Penerimaan } \\
(\mathrm{Rp} / \mathrm{Ha})\end{array}$ \\
\hline 1 & organik & 15.000 & 572,00 & $3.996,67$ & $8.580 .000,00$ & $59.950 .000,00$ \\
2 & non organik & 7.600 & 987,86 & $4.394,84$ & $7.510 .357,14$ & $33.420 .833,33$ \\
\hline
\end{tabular}

Sumber : diolah dari data primer 2016

Berdasarkan hasil penelitian pada Tabel 2 di atas terlihat bahwa petani responden penanaman secara organik di Eka Setia Lestari mendapatkan produksi sebesar 572,00 $\mathrm{kg}$ diperoleh rata-rata penerimaan sebesar $\mathrm{Rp}$ 8.580.000,00, sedangkan penerimaan petani responden penanaman secara non organik dengan mendapatkan produksi sebesar 987,86 $\mathrm{kg}$ memperoleh rata-rata penerimaan sebesar Rp 7.510.357,14.

\subsection{Pendapatan usahatani}

Pendapatan usaha tani menurut Hastuti (2007) merupakan selisih antara penerimaan dan semua biaya, atau dengan kata lain pendapatan meliputi pendapatan kotor atau penerimaan total dan pendapatan bersih. Pendapatan kotor atau penerimaan total adalah adalah nilai produksi komoditas pertanian secara keseluruhan sebelum dikurangi biaya produksi.

Pendapatan usahatani wortel di Pusat Pelatihan Pertanian dan Perdesaan Swadaya (P4S) Eka Setia Lestari diperoleh dari selisih antara penerimaan dengan total biaya produksi. Besarnya pendapatan didapat dari produksi yang dihasilkan dikalikan dengan harga jual wortel lalu kurangi total biaya produksi. Berikut penjelasan pendapatan usahatani wortel selama satu kali musim tanam yang meliputi biaya usahatani wortel, penerimaan, dan pendapatan yang diterima petani wortel di Pusat Pelatihan Pertanian dan Perdesaan Swadaya (P4S) Eka Setia Lestari, Desa 
Bangli, Kecamatan Baturiti, Kabupaten Tabanan selama Periode Musim Tanam September - November tahun 2015 dapat dilihat pada tabel 3 berikut ini.

Tabel 3.

Rata-rata Pendapatan Usahatani Wortel secara Organik dan Non Organik Periode Musim Tanam September - November 2015

\begin{tabular}{lrcrr}
\hline \multicolumn{1}{c}{ Uraian } & $\begin{array}{c}\text { Organik } \\
(\mathrm{Rp} / \mathrm{LLG})\end{array}$ & $\begin{array}{c}\text { Non Organik } \\
(\mathrm{Rp} / \mathrm{LLG})\end{array}$ & \multicolumn{1}{c}{$\begin{array}{c}\text { Organik } \\
(\mathrm{Rp} / \mathrm{Ha})\end{array}$} & \multicolumn{1}{c}{\begin{tabular}{c}
\multicolumn{1}{c}{ Non Organik } \\
$(\mathrm{Rp} / \mathrm{Ha})$
\end{tabular}} \\
\hline Penerimaan (1) & $8.580 .000,00$ & $7.510 .357,14$ & $59.950 .000,00$ & $33.420 .833,33$ \\
Total biaya (2) & $933.553,33$ & $1.319 .128,08$ & $7.191 .766,67$ & $7.713 .434,46$ \\
\hline Pendapatan $(3)=(1-2)$ & $7.646 .446,67$ & $6.191 .229,06$ & $52.758 .233,33$ & $25.707 .398,88$ \\
\hline
\end{tabular}

Sumber : diolah dari data primer 2016

Berdasarkan tabel 3 rata-rata pendapatan petani responden metode penanaman secara organik sebesar $\mathrm{Rp} 7.646 .446,67$ jumlah tersebut didapatkan setelah biaya penerimaan sebesar Rp 8.580.000,00 dikurangi total biaya produksi sebesar Rp 933.553,33, sedangkan pendapatan responden metode penanaman secara non organik sebesar $\mathrm{Rp}$ 6.191.229,06 yang didapat setelah biaya penerimaan yang sebesar Rp 7.510.357,14 dikurangi biaya produksi sebesar Rp 1.319.128,08.

\subsection{Uji Mann Whitney}

Uji U Mann-Whitney merupakan pengujian untuk mengetahui apakah ada perbedaan nyata antara rata-rata dua polulasi yang distribusinya sama, melalui dua sampel independen yang diambil dari kedua populasi. Data untuk uji U MannWhitney dikumpulkan dari dua sampel yang independen.Siegel (1986) mengemukakan bahwa jika tercapai setidak-tidaknya pengukuran ordinal, pengujian Mann-Whitney dapat dipakai untuk menguji apakah dua kelompok independen telah ditarik dari populasi yang sama.

Hasil uji statistik non parametrik menggunakan uji Mann Whitney antara pendapatan petani wortel organik dan non organik dapat dilihat pada Tabel 4 berikut. 


\section{Tabel 4.}

Hasil Uji Mann Whitney terhadap Pendapatan Petani Wortel Organik dan Non Organik Periode Musim Tanam September - November 2015

\begin{tabular}{llccc}
\hline & \multicolumn{3}{c}{ Ranks } \\
\hline \multirow{1}{*}{ Pendapatan } & Kelompok & $\mathrm{N}$ & Mean Rank & Sum Of Rank \\
& Non Organik & 14 & 7,50 & 105,00 \\
& Organik & 10 & 19,50 & 195,00 \\
\hline & Total & 24 & \\
\hline \multicolumn{4}{c}{ Test Statistics $^{\mathrm{b}}$} & Pendapatan \\
\hline & &, 000 \\
Mann-Whitney U & & 105,000 \\
Wilcoxon W & & $-4,099$ \\
Z & &, 000 \\
Asymp. Sig. (2-tailed) & &, $000^{\mathrm{a}}$ \\
Exact Sig. [2*(1-tailed Sig.)]
\end{tabular}

sumber : diolah dari data primer 2016

Berdasarkan hasil menggunakan program SPSS versi 17.0 pengujian analisis perbedaan pendapatan dua kelompok independen dengan uji Mann-Whitney $U$, terlihat pada tabel diatas bahwa diperoleh nilai Asymp. Sig adalah 0.<0,05, artinya hipotesis H0 ditolak yaitu terdapat perbedaan signifikan antara pendapatan petani yang menanam wortel secara organik dan non organik.

Pendapatan petani wortel secara umum dipengaruhi oleh biaya dan harga produk. Pada penelitian ini penyebab pertambahan biaya yang dikeluarkan oleh petani wortel non organik adalah akibat adanya penggunaan pupuk kimia oleh petani wortel non organik, perlunya menyewa pick up untuk membawa hasil produksi ke pasar, petani wortel non organik perlu membeli obat-obatan untuk mengatur hama yang menyerang wortel (Tabel 1), dan harga wortel non organik yang lebih murah dibandingkan wortel organik (Tabel 2). Empat faktor tersebut yang menyebabkan terjadinya perbedaan yang signifikan pada pendapatan wortel organik dan non organik.

\subsection{Kendala}

Kendala yang umum dihadapi oleh para petani wortel non organik adalah harga wortel yang selalu berfluktuasi. Penjualan tanaman wortel pada musim sebelumnya dapat mencapai harga $\mathrm{Rp} 30.000 / \mathrm{kg}$ namun pada penjualan wortel musim tanam September - November 2015 hanya mencapai rata-rata $7.600 \mathrm{Rp} / \mathrm{kg}$ dan pada musim berikutnya belum tentu mendapatkan harga yang sama pada penjualan wortel non organik yaitu harga yang lebih rendah lagi dibanding musim yang sebelumnya sedangkan petani wortel organik tidak mengalami kendala dalam harga produksi karena petani wortel organik melakukan penjualan produksi berdasarkan kontrak terhadap konsumen sehingga harga produk wortel organik tidak mengalami perubahan. 
Kendala yang umum dihadapi oleh para petani wortel organik adalah perlu ketelitian dalam perawatan tanaman wortel sehingga tanaman wortel tersebut tidak mati terserang penyakit ataupun hama karena dengan tidak menggunakannya obatobat para petani harus mampu mengawasi dan menemukan tanda-tanda apabila tanaman wortel tersebut diserang oleh hama serta penyakit sedangkan petani non organik tidak menemui kesulitan dalam perewatan tanaman wortel karena menggunakan insektisida sehingga tanaman wortel lebih jarang terserang penyakit ataupun hama.

\section{Kesimpulan dan Saran}

\subsection{Kesimpulan}

Berdasarkan hasil analisis dan pembahasan pada bab sebelumnya maka dapat disimpulkan bahwa

1. Produktivitas responden wortel organik adalah $572,00 \mathrm{~kg}$ dengan pendapatan sebesar Rp 7.646.446,67, sedangkan pada responden wortel non organik produktivitasnya adalah 987,86 $\mathrm{Kg}$ dengan pendapatan sebesar Rp 6.191.229,06. Hasil uji Mann-Whitney $U$, diperoleh hasil nilai $\alpha$ sig adalah $0<0,05$, artinya hipotesis $\mathrm{H} 0$ ditolak yaitu terdapat perbedaan signifikan antara pendapatan petani yang menanam wortel secara organik dan non organik.

2. Petani organik lebih rentan terhadap serangan hama dan penyakit. Petani non organik memiliki kendala dari segi harga jual yang berfluktuasi.

\subsection{Saran}

Dari uraian penelitian, maka dapat disampaikan saran sebagai berikut.

1. Perlunya adanya penyuluhan di Pusat Pelatihan Pertanian dan Perdesaan Swadaya (P4S) Eka Setia Lestari bagi petani organik untuk mengatasi serangan hama penyakit pada wortel secara biologi atau non kimia.

2. Dapat dilakukannya beberapa cara pencegahan untuk mengurangi kemungkinan tanaman terserang penyakit tersebut yaitu: menanam beberapa jenis dalam satu lahan yang sama dan melakukan pola pergiliran tanaman.

\section{Ucapan Terimakasih}

Penelitian ini tidak mungkin terlaksana tanpa adanya bantuan berbagai pihak, maka dari itu pada kesempatan ini penulis menyampaikan rasa terimakasih kepada ketua Pusat Pelatihan Pertanian dan Perdesaan Swadaya (P4S) Eka Setia Lestari yaitu I Wayan Runca, seluruh responden penelitan yaitu Petani di Pusat Pelatihan Pertanian dan Perdesaan Swadaya (P4S) Eka Setia Lestari, serta seluruh pihak yang membantu kelancaran penelitian ini.

\section{Daftar Pustaka}

BPS Provinsi Bali. 2013. Bali dalam Angka. Badan Pusat Statistik Provinsi Bali. Denpasar 
Hastuti, Diah Dwi Retno. 2007. Pengantar Teori dan Kasus: Ekonomika Pertanian. Penebar Swadaya. Jakarta

Untung, Kasumbogo. 1994. Peranan Hortikultura dalam Perbaikan Lingkungan Hidup. Proc. Simp. Hort. Nas. Malang.

Oladele, O.I. 2011. Contribution of Indigenous Vegetables and Fruits to Poverty Alleviation in Oyo State. Nigeria.

Mubyarto. 1989. Pengantar Ekonomi Pertanian. LP3ES. Yogyakarta

Siegel, Sidney. 1986. Statistika Nonparametrik Untuk Ilmu-Ilmu Sosial. PT Gramedia Pustaka Utama. Jakarta

Soeharjo dan Patong, D. 1973. Sendi-sendi Pokok Usaha Tani. Departemen Ilmuilmu Sosial Ekonomi Fakultas Pertanian Institut Pertanian Bogor. Bogor

Soekartawi. 1986. Ilmu Usahatani dan Penelitian untuk Pengembangan Petani Kecil. UI Press. Jakarta

Sunu, P. dan Wartoyo. 2006. Dasar-dasar Hortikultura (on-line). http://pertanian.uns.ac.id/ agronomi/dashor.html, diakses pada tanggal 5 Januari 2016

Sutanto,R. 2006. Pertanian Organik. Gramedia. Yogyakarta 